corporations, communities and municipalities-such agency to report through the executive annually and at such other times and in such modes as the congress may require. It should be among the first duties of the federal agency to confer with officers or other competent representatives of states concerning water-power and other uses of water with a view to determining means of effective cooperation, equitable sharing of rights and responsibilities, estimates of cost of works required for state and federal use, reasonable rates for domestic and irrigation water supply and for power, and all other matters of common concern to the state and federal governments - the determinations to be reported to the state legislatures and to the congress as a basis for further action in the public interest in accordance with the righteous principles of the greatest good to the greatest number for the longest time.

38. While it is not necessary and might be inexpedient for current federal legislation to specifically declare the principle that all the water of the country belongs to all the people of the country, the enactments may not equitably, nor judiciously in view of the trend of that public sentiment in which lies the power of the nation, be open to construction as dissenting from or denying that principle; for already this has become part of the body of ethical conviction underlying American character and constituting its strength.

W J MCGeE

\section{UNIVERSITY EXTENSION AND THE STATE UNIVERSITY ${ }^{1}$}

THE state university is a public service corporation. It is supported by the public presumably for the public. Until within

${ }^{1}$ Presented before Section L, American Association for the Advancement of Science, at the Minneapolis meeting.' comparatively recent years, few questions have been asked as to the quality and comprehensiveness of the service offered by the university to this constituency, but the time has arrived when not only educators, but intelligent laymen, including both employer and employed, are asking to what degree the relation of the people as a whole to the educational system has been recognized.

What proportion of the young folk who become high school students are served in future years by the university? What proportion of those who remain in school for elementary training only, reap more than the most meager benefits from our socalled popular education?

The high average percentage of illiteracy in the United States, the low comparative degree of efficiency in the industries and the avidity with which opportunities for further training are embraced by persons who have completed their formal education, all point to a fault in the existing system, for which there is at present no generally adopted remedy.

It is not my purpose to dwell upon the shortcomings of our public education, nor to enlarge upon the fact that statistics relating to school attendance would give less cause for discouragement if we recognized in our public schools the value of training for efficiency. A radical change in the curriculum, aimed at retaining the interest of the pupil by showing him the value of his education as a usable asset, would tend to lengthen the term of school life for both boys and girls and, in many cases, would prolong it into and through the university.

In view of this lack of what may be called vocational applications in school training, it is not difficult to understand the reason for the almost overwhelming demand from persons engaged in business pursuits for an opportunity to enter, how- 
ever late in life, upon serviceable courses of study.

It is a question upon which opinions differ, whether or not the university is the source from which extension teaching in its present development should emanate, but so long as there is no other agency prepared to do the work, the question admits of an affirmative answer only.

There is much to be said in favor of a policy which associates with the university the work of extending educational advantages to the people in their homes and places of employment. A measure presenting such immense possibilities of usefulness to the whole people, would seem to belong as an organic part to the state educational work. In order to secure permanence of establishment and growth, extension teaching must be given assured and liberal support, and for reasons of economy and convenience its central offices should be placed where the resources of the great head of the state system would be available for its use. The value of this association has been demonstrated in the success of agricultural extension, which could not have flourished apart from the agricultural college, whose instructional force, facilities for research and material equipment have been essential to its usefulness.

Although close affiliation with the residence work of the university is important, this does not imply that extension instruction shall be limited to courses of study of university grade, nor even that it shall conform necessarily to any conventional schedule of studies. The range of extension activities includes not only such courses as entitle the student to credit toward university or advanced degree, school teacher's diploma or other certified recognition, but also short courses and conferences not leading to a degree, and the promotion of a great variety of interests that reach the people, both young and old, in the intimate relations of their daily life.

In this breadth of scope is seen the vital spirit that animates the new conception of university extension-the spirit of boundless liberality, which would make useful to the entire people, in whatever place, in whatever walk of life, that great fund of knowledge which accumulates and is available at a university, be it the product of research, scholarship or of great gifts of mind and heart.

Having conceded the point that the state university is the natural and proper guardian of the educational interests of the whole people of the state, existing under an obligation to those who can not enter her walls similar to that she owes to her resident student body, we are confronted by the paramount question of method by which every part of the state shall be reached by the university without duplication of machinery, yet effectively and thoroughly. In order to solve this problem of covering the field without waste of effort, it is probable that no method can be absolutely successful which does not involve division of the state into districts having local headquarters, from each of which the various activities of extension shall be promoted within the limits of its territory. The organization may then be compared to a great wheel of which the hub is the university, the rim the boundaries of the state, and the spokes the lines which divide the whole into districts. At the hub, or central headquarters, will be located the dean or director, the several secretaries of departments and the specialists who offer lecture courses, prepare correspondence-study lessons, publish bulletins designed to aid the student in the study of topies for debate, or gather, classify and hold ready for the applicant, instructive literature on a wide range of subjects useful to the stu- 
dent as a private individual or as a citizen of state or municipality.

At the district headquarters will be placed a superintendent, field organizers and local teachers. The working plant will include, in addition to offices for administrative purposes, class rooms, laboratories and library facilities, conveniently situated for the use of groups of students.

The problem of finding a staff of extension workers possessing the very special qualifications required of them is a serious one, but extension teaching is itself assisting in the preparation of suitable men and women to carry on its work, and furthermore, with the introduction of new methods, extension has ceased to depend solely upon a staff of lecturers who must combine the qualities of public speaker, scholar and philanthropist. An organization similar to that outlined in the foregoing pages, so differentiates and distributes the work that there is no longer the necessity, as in the older forms of university extension, to find men who unite in their individual persons a large number of qualifications. Nevertheless, it must be recognized that certain qualities in the extension worker are of essential importance. The district representative, for instance, must be selected with the most painstaking care, and must combine the tastes and training of a social worker with business acumen, and acceptable personality. His training should have been sufficiently liberal to enable him to understand conditions in his community as they are affected by business relations. If the leading industry of his district is agricultural, he should possess some knowledge of agricultural interests ; if manufacturing, he should be more or less of an engineer; if commercial, he should be acquainted with commercial processes. $\mathrm{He}$ is the representative for his district of all the specialists of the university, and the knowledge re- quired of him is such as will enable him to place at the service of the people with whom he is related the resources of the state educational center.

Thus far, little has been said of the actual processes of instruction to be carried on by means of the machinery so fully. described. Correspondence-study, debating and informal discussion, lecture, information and welfare service may be included in its scope.

It will not be possible in the short time that should be consumed by this paper to enter fully into description or even enumeration of the activities through which the university may serve individuals or communities in all parts of the state.

Detailed description of correspondencestudy teaching may be omitted. Its processes are well known and for many years were discredited. At present, it is coming to be accepted as a valuable educational method. In conjunction with weekly or bi-weekly classes, in which the student is brought into personal touch with the instructor, it serves usefully in teaching the industrial employee, whose conditions of life and training as a rule are not favorable to close or unassisted application. While with the trained student, experience goes to prove that correspondence-study may present decided advantages. The testimony of several teachers in The University of Wisconsin, where skepticism prevailed a few years ago, may be of general interest in this connection.

From the head of the department of German in the university :

We have given correspondence courses in almost all branches of the work of the German department-in grammar, reading, composition, literature, philology and methods of teachingand these courses when pursued by students of adequate general preparation and maturity have regularly yielded very valuable results in the imparting of both training and knowledge. 
I entirely share the opinion of Professor Prokosch, who has carefully watched the results of the work, that former correspondence students entering our university classes have proved that they had derived a full measure of benefit from their work. I may add, however, that I believe such satisfactory results are only where, as at the university, in our case, there is close and harmonious cooperation between the general management of the correspondence work, the instructor actually doing the work, and the regular University department in which the work falls.

From an associate professor of history:

The lesson papers of almost all of my pupils have been of good quality, evincing painstaking and thoroughgoing study and power in the subject. The results of the final examinations have been uniformly good. The three correspondence subjects in which I have had most pupils have been Greek history, medieval history and English history.

At the same time that I have been conducting this history study by correspondence, I have been having quiz sections in these same subjects with pupils in attendance at the university. It is natural that I compare the performance of these two sets of pupils. The requirement made of correspondence pupils was as great as of the residence pupils. The text-books were the same, and the ground covered in each subject was the same for each set. The results obtained from the best of the pupils in correspondence work were fully as good as those from the best in residence work, and the average quality of the correspondence work was superior to the average quality of the work done in residence. This last fact is doubtless due to this, that in a large degree these pupils are a naturally selected group. It is well enough recognized that the thirst for knowledge is by no means the only motive that induces a student to enter college, or to continue there. It is, however, the principal motive that prompts the correspondence pupil to undertake the work and this makes and keeps him very responsive to the teacher's efforts.

A correspondence instructor in Latin says :

I have discovered that the students do more work in these Latin courses than they do in the same work as resident students, a fact that the head of the Latin department in the university has found out recently quite apart from my own discovery.
An instructor in the English department, who also has experience in both university and correspondence work, says:

The student in correspondence work has far more individual teaching than is possible in classroom work, and he comes into closer touch with his instructor, who knows his environment, his ambition and his special needs, and is therefore interested to teach him-not only as a student in general, but as an individual in particular. It is a fair statement that I am in closer touch with each of my correspondence students than I could be with one tenth of them in residence, and $I$ have had many pleasant letters expressing delight that this condition really exists.

You may remember that I rather regretted giving up my teaching to work in the extension division, because I believed so firmly in the value of individual instruction. One of the pleasant surprises in my correspondence work has been the opportunity to continue to do individual teaching.

Unquestionably, the correspondence student loses that intangible something we hear so much about, which university life gives and which many value highly. On the other hand, his work receives closer supervision than that of the resident student and his relations with his teacher, as shown by the letters quoted, are more intimate, though of a different character. The student who takes work by correspondence is usually mature. In residence, he would belong to that class of university student which does not identify itself with many of the ordinary student activities. Consequently, he does not lose so much by doing his work away from the university, and it should not be forgotten that those who take part of their work by correspondence are usually persons who, were it not for this opportunity, would never enter the university at all.

Correspondence study, for purposes of university extension, must include courses of practically every grade. The teaching force must be selected with special reference to the peculiar relations between 
teacher and student. The residence instructor is frequently not well adapted to this work. I fully agree, however, with the head of the German department, whose views I have quoted, that the work for credit must be under the careful supervision of the residence departments, since they are responsible to the university for the maintenance of a standard. The work of applicants for degrees, non-resident or resident, must, of course, conform equally to this standard.

Department supervision is, in general, not necessary for the vocational courses, and is not as a rule desirable. There is danger that the influence of the old academic spirit may operate to make vocational correspondence study as applied to industrial workers ineffective and practically valueless. Professional men, including lawyers, physicians, clergymen, teachers and the like, will, naturally, select courses of study that are closely related to the resident work. But a different treatment is required for students of the industrial class who, though mature in years, are immature in mental processes. Many of these have no fixed habits of study, or are unaccustomed to confinement out of working hours, and frequently realize only imperfectly the benefits to be derived from a course of study applied to their vocation. They are often burdened by home cares. The fact that the fee, however small, would help to lighten the home burdens will often affect their judgment, and the present is more significant to them than the future. These students need constant encouragement with close personal contact. They must be shown in the class room, in the shop, or the local laboratory the application of their instruction to the industry in which they are employed. An occasional meeting in the class room under the direction of an instructor, where notes and ex- periences in the work can be compared, acts as a helpful stimulus.

The method of instruction which combines correspondence study with class work, applied under the conditions of such district organization as has been described, has been successfully applied. In mining districts classes of industrial workers engage under local direction in courses of study designed to improve their proficiency in mining engineering; in manufacturing districts, shop mathematics, machine construction and other subjects fundamental to mechanical processes are studied; in commercial centers, business courses; in rural districts, agricultural subjects; in fact, university extension effectively administered through district organization should offer vocational training in every part of the state directly applicable to the prevalent conditions.

An interesting and valuable phase of extension work has to do with choice of occupation. The Vocational Bureau in Massachusetts has demonstrated that a large field of usefulness is open to the instrumentality that has for its object guidance of the individual, whether young or old, toward the selection of an occupation adapted to his abilities and tastes. Many a man is a failure because he is in the wrong place. The bootblack who is shown the way to fit himself for more remunerative and agreeable work, the clerk who is helped to achieve the broader usefulness for which he has ambition and capacity, in a word, every misfit who is assisted to discover and develop his peculiar abilities becomes a more valuable unit to himself and his community. It is evident that district organization may be a useful agent in bringing the needed opportunity to persons whose latent possibilities are worthy of recognition and development.

Other activities of the district force will 
include the introduction of lecture courses; the organization of debating or other clubs; the formation of night classes; the spread of library facilities; the opening of laboratories; the promotion of educational measures in business organizations; the assistance of town or rural communities in civic or social improvement; the conduct of institutes or conferences-the number of these activities is too great for enumeration. The district representative's acquaintance with the people and the organizations in his district, having for their object industrial; social or civic betterment, will enable him to place the university at their service.

An important possibility for extension activity is that which would bring the work of the great research departments of the nation, the state and the university within the grasp of the people to whom their results would be valuable, if spread abroad in terms suited to the layman's comprehension.

Scores of men are at work for the state, and for the nation, solving problems affecting industrial and commercial conditions, whose results never reach the people at large, or do so after costly delays. Much of this information is gathered at a cost of millions of dollars and would be of incalculable value if properly disseminated. It is not sufficient to determine in the laboratory that coal should be purchased on the basis of number of heat units in a pound, other things being equal, but this fact must be made known to coal users or buyers if it is to be of real value. Results obtained by experts and specialists to be of general use must be put into simple and direct form and brought to the knowledge of the people.

The need of the general public for nonpartisan and dispassionate information upon the live problems of the day, political and other; the want in many places of library facilities for the study of such ques- tions, or in the presence of the library, the lack of knowledge of its contents and how to use them; also the demand from schools for aid in arousing the interest of growing boys and girls in the issues that are before the country, all point to a fruitful field of university service. The policy is surely questionable, at least, which leaves to the press and political orators the education of the public in matters so essential to its welfare, as, for example, election of senators by popular vote, good roads, the wheel tax, commission form of city government, the recall, etc.

Existing organizations, of which there are many-such as civic clubs, women's clubs, business men's clubs, commercial clubs, debating clubs, ete.-and groups of people needing only a suggestion to lead them to form themselves into bodies for study and discussion, are anxious to consider the newer questions of the day, but often do not know where to turn for advice and assistance. There should be available at the university for the use of these organizations, collections of classified reference material in the shape of newspaper and magazine articles, books, and state and national publications relating to those subjects, to be lent under definite regulations free of cost.

There should also be published and distributed bulletins formulating subjects for debate and containing full lists of references, negative and affirmative, with information as to where and how they may be obtained. State traveling library commissions should cooperate in the work. In fact, as traveling libraries have such an important relation to all university extension work, it is a question whether the traveling library commission should not have an organic relation with university extension.

Topical package libraries, adapted to 
high-school work in preparation of graduation themes and debates may be used to awaken interest among boys and girls in current questions. It will be found that high-school teachers are glad to divert their students from the old stereotyped subjects to live modern ones, when it is not too difficult to obtain reliable and timely information.

The wisdom of the establishment of a municipal reference bureau as a university charge will not be questioned when it is remembered that in a little over one hundred years urban population in the United States has increased from two per cent. of the total population to nearly fifty per cent. So rapid a growth as this must tax the powers of the legislator to the utmost, and is sure to be accompanied by an amount of groping in the dark and experimentation that may be disastrous. Large cities can well afford to establish bureaus of their own, manned with experts in municipal government, but such a course is absolutely impossible for the smaller municipalities and rural districts.

There is a general awakening to the need for better urban government, and recognition that this country is far behind many foreign countries in city administration. But it is seldom that the council of a town or small city will take the trouble to gain or even feels the need for information regarding practises and results in other places.

A university offers exceptional facilities for carrying on this work. Ordinances collected and filed for reference, together with data relating to their effectiveness as working measures, will be conveniently available through extension division channels. And the same instrumentality will connect the municipality with the service in a purely advisory capacity of the university specialist in such departments as sanitation, hygiene, street lighting or paving, and all matters affecting the general welfare of the people.

Frequently, in great movements, much effort is wasted in the creation of interest and enthusiasm, which is not sustained because no agent is at hand to keep the impulse alive until it is crystallized into permanent form. The crusade against tuberculosis, the schoolhouse social center movement, and many other similar undertakings of vital and far-reaching effect upon large numbers, would be much more surely advanced if controlled by such organization as belongs to university extension, than is possible under the ordinary conditions of inertia or spasmodic attack, which characterize the average community.

The experiment of cooperation between the Anti-tuberculosis Association and the university has been tried with marked success, and the social center movement is also recognized as a suitable $\vec{w}$ ork for university promotion.

The bringing together in united interests of groups, diversified in racial, political, religious and social affiliations is a step tending toward a more genuine democratization of the American people than has yet been experienced in their life or their institutions. The use of the schoolhouse out of school hours and of the public playgrounds for the work and play of people of all ages appeals strongly to the wide-awake educator as an economical, sane and healthful measure, one that provides a remedy for evils that exist both in urban and rural communities. As an educational means, it probably needs, for the present at least, the fostering care of a strong organization, quite as much as any other field of extension endeavor. University extension should find in this civic and social center a suitable vehicle for its operations.

The machinery of university extension 
may legitimately be used in conducting conferences of interest to certain classes of workers. These may include conventions covering several days, or institutes of several weeks' or months' duration. An organization having the resources of the university at its command can easily assemble specialists in some given subject as, for example, civic and social service, criminology or the scientific aspects of a craft. Lectures, demonstrations and informal discussions are directed toward plain and lucid exposition of the problems under consideration. Authorities, not only from the university, but from over the whole country may be drawn upon for these conferences, with the result that the work will be up-to-date, scientific, practical and comprehensive in its applications.

One of the most widely known and gifted extension lecturers in our country wrote a year or two ago of the university extension movement :

Like all ideas and movements, it has fulfilled itself in unseen ways. It is no longer an occasional and accidental phase of university work; it is an organic part of it. It is no longer concerned merely or primarily with short lecture courses, for without neglecting the lecture work that appeals to general audiences, it aims to reach, like any other part of the university, a student body ... the very large body of partial or nonresident students.

Examination into the status of extension teaching in the United States discloses a remarkable broadening and liberalizing of the academic spirit. The fact that a number of the old conservative universities now offer extra-mural teaching with no more stringent specifications than that the applicant shall be able to show that he can take the work to advantage, is evidence of a notable change in their educational atmosphere.

The uniting of the eight leading educational institutions in and around Boston, including Harvard, Tufts, the Massachusetts Institute of Technology and others, into a Commission on Extension Teaching, denoted a striking departure from the old conception of higher education. The fact that these institutions have agreed upon a course of instruction leading to the degree A.A. (associate in arts) with no entrance examination or resident work requirements, is evidence of a radical readjustment of viewpoint among educators.

The cost of extension teaching, state-wide in its application, must necessarily seem formidable, but it must be recognized that not only does the system promise a degree of amelioration of economic and other conditions, but gives immediate and substantial returns in increased productive power of the trained over the untrained worker.

In 1907-08, according to the Commissioner of Education, the sum of $\$ 66,790,924$ was spent in giving higher education in the United States to 265,966 persons. In the state of Minnesota $\$ 1,880,568$ were spent in the same year for the education of 6,743 persons. No one acquainted with the facts will question the wisdom of this expenditure. Educated leadership is essential; the results of research as conducted in institutions of higher learning are far reaching, the value incalculable. Yet, if the state university is in truth a public service corporation, is not the public justified in demanding that this great expenditure be made to serve the entire state as its student body? Nor should the fact be overlooked that the extra-mural aetivities of university extension create an attitude in the people of the state, that will not fail to be reflected in greater loyalty and more generous financial support-conditions that may be counted upon not only to insure the spread of university benefactions, but to more rapidly advance the interests of the 
conventional and long-established forms of higher educational work.

THE UNIVERSITY OF WISCONSIN

$$
\text { LouIs E. REBER }
$$

AN OPPORTUNITY FOR THE SPIRIT OF RESEARCH IN LABORATORY INSTRUCTION IN PHYSICS

A ritual does not require worship; a system in laboratory instruction does not demand the investment of the personality of the instructor. A smoothly operating system is a delight to the mill owner or to the manufacturer. According to general practise, such a system affords the modern laboratory instructor in physics a great deal of satisfaction.

But has not laboratory instruction in physics become enslaved to laboratory methods? The fundamental purpose of such instruction should be decided in the light of its origin. At first the laboratory work was not prescribed in the course of study. Magnus ${ }^{1}$ in Berlin conducted such a laboratory. The experiments performed were of an investigational nature. Some of his pupils were G. H. Wiedemann, Helmholtz and Tyndall. Later, Lord Kelvin, ${ }^{2}$ at Glasgow, entered upon certain investigations of the electrodynamic qualities of matter and, finding the labor of observing too heavy for one individual, invited certain students to aid in the work. Other students desired experimental work of a similar nature and thus was developed a research laboratory in which the students took an enthusiastic interest. The funds of this laboratory were obtained from the university, but, in the beginning, there was no systematic instruction of students similar to that in the laboratories of to-day.

As these two illustrations indicate, the student's physical laboratory had its origin in research. The zeal for new knowledge furnished the enthusiasm and prescribed the methods of work. To-day, apparently, the student enters the laboratory to learn how to perform experiments and to become expert in

${ }^{1}$ Cajori, "History of Physies," p. 291.

${ }^{2}$ From Kelvin's Bangor address, quoted in Gray's "Lord Kelvin," p. 71. the use of various devices such as the micrometer microscope, or the optical lever, or the dividing engine, and to familiarize himself with certain methods of measurement, such as the method of coincidences or the method of double weighing. Indeed, quite frequently courses have such titles as "Laboratory practise" and "Electrical measurements."

Jesus claimed that the Pharisees tithed mint, anise and cummin, but neglected the weightier matters of the law. One can not deny the virtue of tithing; neither can one fail to appreciate the educational value of an experiment which requires great care and accuracy on the part of the student. But what about the weightier matters? The chief function of the laboratory is to give the student an intimate acquaintance with the phenomena and the so-called laws. The familiarity of the student with a particular instrument or method is of temporary importance and should be of little interest. Indeed, why should accurate measurements be considered so highly desirable? Do not the thoughtful regret the fact that in the progress of physics so much valuable time must be spent in accurate measurements by the investigators? Does not the physicist seek to obtain the accuracy needed in a particular investigation with the least amount of painstaking effort, and therefore the least time and labor? Accurate measurements are found in research because they are needed to obtain results, and not because they are intrinsically worthy of a scholar's time and attention. Let this be the recognition of accurate measurements in the laboratory of the student.

The Pharisees thought that they were right, and doubtless their attitude can be explained by the powerful influence of tradition. The defect in our present laboratory instruction can be explained in a similar manner. The instructor accepts the laboratory as an approved method of instruction and is not continually conscious of its highest function. The student working under his direction is just " doing laboratory work."

The slavery to method can be resisted only where the true spirit of research is supreme. 